\title{
Analysis of Associative Relationship of Allelic and Genotypical Variants of Polymorphism Rs 2010963 of the VEGFA Gene with Formation and Development of Ronchopathy

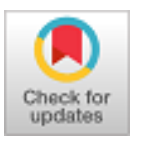

\author{
U.S.Khasanov, S.S.Sharipov
}

\begin{abstract}
It is interesting to note that the adverse effect of this genotype was observed exclusively in patients with ronchopathy, while in patients with ronchopathy, the frequency of this genotype did not differ in comparison with the control group, i.e. there is a significant tendency to an increase in the genotype with an increase in the severity of the pathology. Material and methods. To solve the set tasks, 208 patients with various diseases of the upper respiratory tract, with nasal breathing disorders, causing ronchopathy, who were hospitalized in the ENT department of the multidisciplinary clinic of the Tashkent Medical Academy for 2015 to 2021, were examined. The control group consisted of 50 apparently healthy people who agreed to participate in the study (students, masters, clinical residents). Among the sick men there were 144 (73\%), women - 64 (27\%). The age of the patients ranged from 18 to 70 years, averaging $44.5 \pm 6.8$ years. Molecular genetic studies were carried out in the Department of Molecular Medicine and Cell Technologies of the RSNPMC Hematology. This part of the work consisted of several stages: 1. Blood sampling. 2. Isolation of DNA from peripheral blood lymphocytes. 3. Carrying out PCR. 4. Conducting electrophoresis and visualizing the results (if necessary). The analysis of the TGFb1 gene polymorphism associations was carried out using a case-control model (casecontrol, comparison of two samples). The sample "case" was formed from 104 patients with ronchopathy. Conclusion. Since this work is one of the few works on the study of the relationship between rs 2010963 of the VEGFA gene and the risk of developing ronchopathy, our data may become the subject of further discussions.
\end{abstract} Gene.

Keywords: Ronchopathy, Allele, Genotype, Polymorphism,

\section{INTRODUCTION}

Ronchopathy - synonyms for primary snoring (benign, simple, normal), pathological snoring (chronic, regular, habitual, unusual), snoring [1,2].

Manuscript received on 14 July 2021 | Revised Manuscript received on 20 July 2021 | Manuscript Accepted on 15 August 2021 | Manuscript published on 30 August 2021.

* Correspondence Author

Khasanov Ulugbek Saidakramovich, Doctor of Science, Professor, Department of Otolaryngology and stomatology of Tashkent Medical Academy, Republic of Uzbekistan. Email: u.khasanov@yahoo.com

Sharipov Sanjar Salomovich*, Doctor of philosophy (PhD), Associate Professor, Department of Otorhinolaryngology of Tashkent State Dental Institute, Republic of Uzbekistan. Email: sanjar.shifo@mail.ru

(C) The Authors. Published by Lattice Science Publication (LSP). This is an open access article under the CC-BY-NC-ND license (http://creativecommons.org/licenses/by-nc-nd/4.0/)
Ronchopathy (Greek ronchus-snoring, wheezing) is a chronic progressive disease manifested by obstruction of the upper airways and chronic respiratory failure, leading to syndromic changes in the body of a compensatory and decompensatory nature [3].

Patients with ronchopathy make up a significant part of patients in hospitals and clinics, making a significant contribution to the structure of general morbidity and mortality of the population around the world. Ronchopathy is a multifactorial disease, in the formation of which such endogenous factors as obesity and maxillofacial dysmorphia make a significant contribution. At the same time, phenotypes are distinguished: Ronchopathy and hypertension; Ronchopathy and obesity; Ronchopathy and maxillofacial dysmorphias. [4,5,6,7].

In the general population, about $32 \%$ of men and $21 \%$ of women snore. Snoring causes impaired thermal sensitivity, two-point discrimination, and histopathological changes in the soft palate [8].

In many cases, snoring is underestimated, resulting in a failure to diagnose comorbid conditions such as obstructive sleep apnea (OSA). It is a multifactorial disease in which histological changes, rheological parameters and predisposing factors such as high body mass index, age and male sex play an important role, which lead to disturbed sleep and affect quality of life, significantly increasing the risk of cardiovascular morbidity.

Obstructive sleep apnea / hypopnea syndrome (OSAHS) is a condition characterized by the presence of snoring, intermittent partial or complete cessation of breathing during sleep, prolonged enough to lead to a decrease in oxygen levels in the blood, gross sleep fragmentation and daytime sleepiness [9].

OSAHS is a common pathology and is recorded at any age. OSAHS affects $5-7 \%$ of the world's population over the age of 30 , while OSAHS is severely affected by about $1-2 \%$ of the population [10,11,12,13,14,15]. In the Russian Federation, the prevalence of OSAHS ranges from $10 \%$ in women to $30 \%$ in men [4]. In general, the prevalence of OSAS in the population is from 1 to $13 \%$, while the numbers vary greatly depending on the country, population group and age.

According to the WHO, OSAHS is registered in the middle age group in $4 \%$ of men and $2 \%$ of women, which is close to the prevalence of diabetes mellitus and twice the frequency of severe bronchial asthma [16].

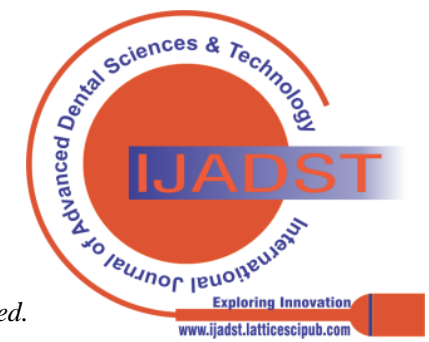



criteria such as apnea / hypopnea index (AHI) and age [17]. Over the past decades, sleep medicine has made significant progress not only in understanding the pathophysiological basis of sleep breathing disorders, but also in the treatment of these disorders [18], however, the issues of OSAHS genetics are far from being resolved [19].

There is growing evidence that genetic factors are involved in the development of OSAHS. In some cases, this pathological condition is clearly genetically determined. The interaction of genes that affect obesity, craniofacial morphology, the occurrence of respiratory disorders, daytime sleepiness, with "favorable" external factors, can lead to the formation of a predisposition to OSAHS, and therefore OSAHS should be considered as a multifactorial (polygenic) hereditary disease. In general, about 35-40\% of all OSAHS cases can be explained by genetic factors [20]. Thus, a number of researchers believe that in the presence of relatives of the first degree of kinship in the family, suffering from OSAHS, the risk of developing this disease in a proband increases more than 2 times compared with the average population [21]. Knowing the contribution of genetic factors to the development of OSAHS, it is easier to understand the pathogenesis of this complex disease, which can be an independent nosology or part of a larger syndrome associated with respiratory, cardiovascular or endocrine dysfunction. Identification of genetic variants that can increase the risk of OSAHS should lead to a decrease in the incidence, timely diagnosis and treatment of this syndrome in the early stages of development.

Although there is compelling clinical and epidemiological evidence supporting the importance of genetic factors in obstructive sleep apnea, its genetic basis is still largely unknown. Previous genetic research has focused on traits identified by the apnea-hypopnea index, which contains limited information about potentially important genetically determined physiological factors such as the tendency to hypoxemia and respiratory irritability. The occurrence of snoring is promoted by disturbed nasal breathing, for example, as a result of the formation of nasal polyps, with adenoids, curvature of the nasal septum, increased body weight in people with a short and thick neck, etc.

To date, no research methodology has been developed that allows one to assess the functional and morphological state of the nasal mucosa in normal conditions, with ronchopathy and obstructive sleep apnea syndrome at the examination stage, and thereby determine the choice of rational treatment tactics for this pathology.

One of the important advances in the study of snoring and OSAS was the emergence of polysomnography (PSG), a fairly objective method for assessing respiratory function during sleep [22].

The variety of existing methods of treating ronchopathy indicates the insufficient effectiveness of each of them, which leads to the need for further research of this problem.

The development of otorhinolaryngology and insurance medicine dictate the need to objectively substantiate indications for surgery and evaluate the results of surgery. Objective examination methods are necessary to understand the norm and pathology of the nasal cavity when making a diagnosis and assessing the outcome of operations. Therefore, the search for objective methods for studying the functional state of the nasal cavity and standardizing the results of the study of nasal
There are three degrees of OSAHS severity according to

breathing remains an urgent problem of otorhinolaryngology, which determined the purpose of this study.

\section{MATERIAL AND METHODS}

To solve the set tasks, 208 patients with various diseases of the upper respiratory tract, with nasal breathing disorders, causing ronchopathy, who were hospitalized in the ENT department of the multidisciplinary clinic of the Tashkent Medical Academy for 2015 to 2021, were examined. The control group consisted of 50 apparently healthy people who agreed to participate in the study (students, masters, clinical residents). Among the sick men there were 144 (73\%), women - 64 (27\%). The age of the patients ranged from 18 to 70 years, averaging $44.5 \pm 6.8$ years.

Molecular genetic studies were carried out in the Department of Molecular Medicine and Cell Technologies of the RSNPMC Hematology.

This part of the work consisted of several stages:

1. Blood sampling.

2. Isolation of DNA from peripheral blood lymphocytes.

3. Carrying out PCR.

4. Conducting electrophoresis and visualizing the results (if necessary).

The analysis of the TGFb1 gene polymorphism associations was carried out using a case-control model (case-control, comparison of two samples). The sample "case" was formed from 104 patients with ronchopathy.

Genomic DNA preparations, both isolated independently and stored in the DNA bank of the RSNPMC Hematology of the Ministry of Health of the Republic of Uzbekistan, were used as material for the control sample. The control group consisted of 50 healthy unrelated donors (Uzbek nationality), matched by sex and age to the examined group of patients ( $\mathrm{p}>0.05)$, and had no history of ronchopathy pathology.

Genetic research and analysis of the data obtained was carried out in accordance with the principles of GRIPS in order to increase the transparency and quality of risk prediction [10].

The AmpliPrime RIBO-prep reagent kit (AmpliSens, Russia) was used to isolate DNA from peripheral blood. The isolated DNA concentrations were measured on a NanoDrop 2000 spectrophotometer (NanoDrop Technologies, USA) at a wavelength of A260 / $280 \mathrm{~nm}$. The purity of all samples of the isolated DNA preparation, determined by the ratio A260 / 280, was 1.7 / 1.8. PCR analysis was performed using Applied Biosystems 2720 (USA) and CG1-96 (Corbett Research, QUAGEN, Germany) thermal cyclers. The following reagents and enzymes were used in the work: acrylamide, bis-acrylamide, EDTA, 5\% glycerol solution, proteinase K (Sigma, USA), TEMED, sodium dodecyl sulfate, Tris-HCL (Serva, Germany), 2 -mercaptoethanol ("Ferax", Germany), deoxynucleotide triphosphates, dideoxynucleotide triphosphates, Triton X100, magnesium chloride, sodium chloride, ammonium sulfate, ammonium persulfate, thermostable DNA polymerase Thermus aquaticus (NPO "Biomereotide" , Novosibirsk),

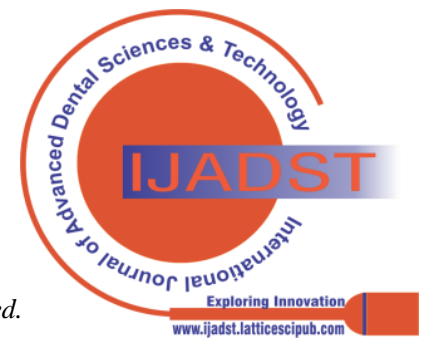


test systems by OOO NPF Litekh (Moscow) and OOO InterLabService (Moscow). For molecular genetic studies, the following equipment was used: Applied Biosystems 2720 (USA) and CG1-96 thermal cyclers (Corbett Research, QUAGEN Germany), and RotorGeneQ (QUAGEN Germany), laminar box (Germany), centrifuges (Eppendorf, Hittich, Germany) , vortex (Eppendorf, Germany), thermostats, spectrophotometer NanoDrop 2000 "Thermo Scientific" (USA), device for horizontal electrophoresis, power source (DNA-Technology, Russia), UV transilluminator with built-in digital camera, automatic pipettes (Sartorius, Finland ) and etc.

\section{RESULTS AND DISCUSSION}

The associative analysis of the rs 2010963 locus of the VEGFA gene in the studied groups of patients with ronchopathy and control was also carried out using the casecontrol design. The obtained results of the detection of this data are presented in Table 1 and indicate the presence of a contribution of the unfavorable allele $\mathrm{G}$ and the associated $\mathrm{C}$ / G genotype in the development of ronchopathy.

Table 1 Differences in the frequency of allelic and genotypic variants of the rs 2010963 polymorphism of the VEGFA gene in patient groups

\begin{tabular}{|c|c|c|c|c|c|c|c|c|c|c|c|c|}
\hline \multirow{3}{*}{$\begin{array}{l}\text { Alleles and } \\
\text { genotypes }\end{array}$} & \multicolumn{4}{|c|}{$\begin{array}{l}\text { Number of examined alleles } \\
\text { and genotypes }\end{array}$} & \multirow{3}{*}{$\mathrm{Xi2}$} & \multirow{3}{*}{$\mathrm{p}$} & \multirow{3}{*}{$\mathrm{RR}$} & \multirow{3}{*}{$\begin{array}{c}- \\
95 \% \mathrm{C} \\
\mathrm{I}\end{array}$} & \multirow{3}{*}{$\begin{array}{c}+ \\
95 \% \mathrm{C} \\
\quad \mathrm{I}\end{array}$} & \multirow{3}{*}{ OR } & \multirow{3}{*}{$\begin{array}{c}- \\
95 \% \mathrm{C} \\
\text { I }\end{array}$} & \multirow{3}{*}{$\begin{array}{c}+95 \% \\
\text { CI }\end{array}$} \\
\hline & \multicolumn{2}{|c|}{ Main group } & \multicolumn{2}{|c|}{ Control group } & & & & & & & & \\
\hline & $\mathrm{n}$ & $\%$ & $\mathrm{n}$ & $\%$ & & & & & & & & \\
\hline C & 140 & 67,31 & 158 & 78,22 & 6,14 & 0,61 & 0,86 & 0,59 & 1,25 & 0,57 & 0,37 & 0,89 \\
\hline $\mathrm{G}$ & 68 & 32,69 & 44 & 21,78 & 6,14 & 0,39 & 1,16 & 0,71 & 1,91 & 1,74 & 1,12 & 2,71 \\
\hline $\mathrm{C} / \mathrm{C}$ & 49 & 47,12 & 60 & 59,41 & 3,11 & 0,57 & 0,79 & 0,47 & 1,35 & 0,61 & 0,35 & 1,06 \\
\hline $\mathrm{C} / \mathrm{G}$ & 42 & 40,38 & 38 & 37,62 & 0,16 & 0,50 & 1,07 & 0,63 & 1,83 & 1,12 & 0,64 & 1,97 \\
\hline $\mathrm{G} / \mathrm{G}$ & 13 & 12,5 & 3 & 2,97 & 6,47 & 0,48 & 4,21 & 2,44 & 7,26 & 4,67 & 1,42 & 15,30 \\
\hline
\end{tabular}

As can be seen from Tables 1 and 2, in the studied groups of patients and controls, the proportion of $\mathrm{C}$ and $\mathrm{G}$ alleles was $67.31 \%$ and $32.69 \%$ versus $78.22 \%$ and $21.78 \%$, respectively. Statistical processing, despite insignificant differences, revealed a noticeable trend towards an increase in the frequency of the unfavorable $\mathrm{G}$ allele (with high odds ratios) and a decrease in the dominant, wild $C$ allele in patients with ronchopathy compared to conventionally healthy donors. The calculated odds ratio showed that the chance of detecting a functional unfavorable allele $G$ in respondents with ronchopathy increased by 2.0 times compared to representatives of the control group $(\chi 2=6.14$; $\mathrm{P}=0.39 ; \mathrm{OR}=1.74 ; 95 \%$ CI 1.12-2.71). The calculated relative risk of developing pathology was 1.8 with a confidence interval of 95\% CI 0.71-1.91.

Table 2 Frequency of distribution of alleles and genotypes of the rs 2010963 polymorphism of the VEGFA gene in patient and control groups

\begin{tabular}{|c|c|c|c|c|c|c|c|c|c|c|c|}
\hline \multirow{3}{*}{ Num } & \multirow{3}{*}{ Group } & \multicolumn{4}{|c|}{ Allele frequency } & \multicolumn{6}{|c|}{ Genotype distribution frequency } \\
\hline & & \multicolumn{2}{|c|}{$\mathrm{C}$} & \multicolumn{2}{|c|}{ G } & \multicolumn{2}{|c|}{$\mathrm{C} / \mathrm{C}$} & \multicolumn{2}{|c|}{$\mathrm{C} / \mathrm{G}$} & \multicolumn{2}{|c|}{$\mathrm{G} / \mathrm{G}$} \\
\hline & & $\mathrm{n}$ & $\%$ & $\mathrm{n}$ & $\%$ & $\mathrm{n}$ & $\%$ & $\mathrm{n}$ & $\%$ & $\mathrm{n}$ & $\%$ \\
\hline 1 & Main group $(\mathrm{n}=104)$ & 140 & 67,31 & 68 & 32,69 & 49 & 47,12 & 42 & 40,38 & 13 & 12,5 \\
\hline 2 & $\begin{array}{l}\text { Mild ronchopathy }(\mathrm{n}= \\
67)\end{array}$ & 91 & 67,91 & 43 & 32,09 & 32 & 47,76 & 27 & 40,3 & 8 & 11,94 \\
\hline 3 & $\begin{array}{c}\text { Moderate ronchopathy } \\
(\mathrm{n}=37)\end{array}$ & 49 & 66,22 & 25 & 33,78 & 17 & 45,95 & 15 & 40,54 & 5 & 13,51 \\
\hline 4 & Control group $(\mathrm{n}=101)$ & 158 & 78,22 & 44 & 21,78 & 60 & 59,41 & 38 & 37,62 & 3 & 2,97 \\
\hline
\end{tabular}

The frequencies of C / C, C / G and G / G genotypes rs 2010963 of the VEGFA gene in the studied groups of patients with ronchopathy and control were: 47.12\%, $40.38 \%$ and $12.5 \%$ versus $59.41 \%, 37.62 \%$ and $2.97 \%$, respectively. As can be seen, the frequency of the wild $\mathrm{C}$ / $\mathrm{C}$ genotype among patients with ronchopathy was lower than in the control group ( $47.12 \%$ versus $59.41 \%$, respectively, with $\chi 2=3.11 ; \mathrm{P}=0.57 ; \mathrm{OR}=0.61 ; 95 \%$ CI $0.35-1.06)$. $\mathrm{A}$ tendency to an increase in the number of ancestral homozygote $G$ / $G$ in the control sample was revealed, which indicates a possible protective effect of this genotype in relation to the development of ronchopathy with impaired nasal breathing.

There was also a slight increase in the proportion of heterozygous carriers of the unfavorable genotype C / G among patients compared with the control group (40.38\% versus $37.62 \%$, respectively). According to the odds ratio, the risk of developing ronchopathy with impaired nasal breathing in the presence of this genotype increases by 1.2 times $(\chi 2=0.16 ; \mathrm{P}=0.50 ; \mathrm{OR}=1.12 ; 95 \%$ CI $0.64-1.97)$ (Table 2).As you know, verification of the main group of patients into subgroups, enhances the OR values and allows you to more accurately assess the level of association. Therefore, the next stage of our work was a comparative analysis of the rs 2010963 polymorphism of the VEGFA gene in the subgroups of patients with ronchopathy.

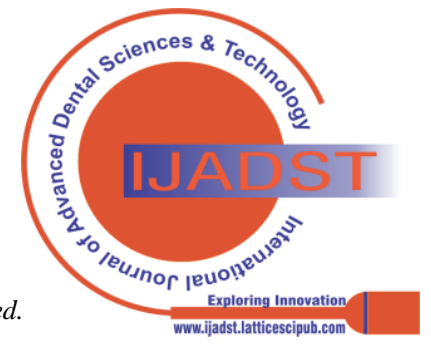


It should be emphasized that when comparing the frequency distribution of alleles and genotypes of this locus in patients with ronchopathy, we did not find significant differences from healthy individuals ( $p>0.05)$.

When comparing the frequencies of alleles and genotypes of the rs 2010963 polymorphism of the VEGFA gene, the concentration of the unfavorable allele $G$ and genotype C / $\mathrm{G}$ was determined with a high frequency in the subgroup of ronchopathic patients compared to the control sample, and a tendency towards difference was recorded.

In patients with ronchopathy, the frequency of the unfavorable $\mathrm{G}$ allele is more than 2 times insignificantly higher than in the control group $(\chi 2=3.0 ; \mathrm{P}=0.08$; $\mathrm{OR}=$ 2.1; 95\% CI0.8881-5.106). The proportion of carriers of the heterozygous C / G genotype among the representatives of this subgroup and control corresponded to $22.9 \%$ and $11.5 \%$, respectively $(\chi 2=3.2 ; \mathrm{P}=0.07 ; \mathrm{RR}=2.0 ; 95 \%$ CI0.88- 2.36; OR = 2.3; 95\% CI 0.915 - 5.768). Here, it is definitely necessary to note a tendency towards an increase in the frequency of the unfavorable G allele and the C / G genotype in patients with ronchopathy compared to conventionally healthy donors. the degree of difference is at the level of static significance.

In this case, the relatively weak correlations in carriers of the unfavorable C / G genotype with the formation of ronchopathy may be associated primarily with a low frequency in the population, as well as a relatively small number of patients in this subgroup. For an unambiguous assessment of the role of the rs 2010963 polymorphism of the VEGFA gene depending on the severity of ronchopathy, of course, additional and in-depth studies are needed with an increase in the number of patients and control.

It should be noted that the allelic and genotypic variants of rs 2010963 of the VEGFA gene among patients with ronchopathy are evenly distributed, the differences found did not reach a statistically significant level $(\mathrm{p}>0.05)$ (Table 3).

Table 3 Differences in the frequency of allelic and genotypic variants of the rs 2010963 polymorphism of the VEGFA gene in patient groups

\begin{tabular}{|c|c|c|c|c|c|c|c|c|c|c|c|c|}
\hline \multirow{3}{*}{$\begin{array}{c}\text { Alleles } \\
\text { and } \\
\text { genotypes }\end{array}$} & \multicolumn{4}{|c|}{$\begin{array}{l}\text { Number of examined } \\
\text { alleles and genotypes }\end{array}$} & \multirow{3}{*}{$\mathrm{Xi2}$} & \multirow{3}{*}{$\mathrm{p}$} & \multirow{3}{*}{$\mathrm{RR}$} & \multirow{3}{*}{$\begin{array}{c}- \\
95 \% \mathrm{CI}\end{array}$} & \multirow{3}{*}{$\begin{array}{c}+ \\
95 \% \mathrm{CI}\end{array}$} & \multirow{3}{*}{ OR } & \multirow{3}{*}{$\begin{array}{c}- \\
95 \% \mathrm{CI}\end{array}$} & \multirow{3}{*}{$+95 \% \mathrm{CI}$} \\
\hline & \multicolumn{2}{|c|}{$\begin{array}{c}\text { Mild } \\
\text { ronchopathy }\end{array}$} & \multicolumn{2}{|c|}{$\begin{array}{c}\text { Moderate } \\
\text { ronchopathy }\end{array}$} & & & & & & & & \\
\hline & $\mathrm{n}$ & $\%$ & $\mathrm{n}$ & $\%$ & & & & & & & & \\
\hline $\mathrm{C}$ & 91 & 67,91 & 49 & 66,22 & 0,06 & 0,63 & 1,03 & 0,67 & 1,57 & 1,08 & 0,59 & 1,98 \\
\hline G & 43 & 32,09 & 25 & 33,78 & 0,06 & 0,37 & 0,98 & 0,46 & 2,07 & 0,93 & 0,51 & 1,69 \\
\hline $\mathrm{C} / \mathrm{C}$ & 32 & 47,76 & 17 & 45,95 & 0,03 & 0,64 & 1,04 & 0,59 & 1,82 & 1,08 & 0,48 & 2,42 \\
\hline $\mathrm{C} / \mathrm{G}$ & 27 & 40,3 & 15 & 40,54 & 0,00 & 0,65 & 0,99 & 0,56 & 1,76 & 0,99 & 0,44 & 2,24 \\
\hline $\mathrm{G} / \mathrm{G}$ & 8 & 11,94 & 5 & 13,51 & 0,05 & 0,65 & 0,88 & 0,36 & 2,16 & 0,87 & 0,26 & 2,87 \\
\hline
\end{tabular}

In tables shows the predictive value (AUC) values of the rs 2010963 polymorphism of the VEGFA gene. As can be seen from the table, the indicators of the level of specificity and sensitivity ( $\mathrm{SE}=22$ ) of this locus significantly deviate towards specificity $(\mathrm{SP}=0.88)$. Despite the high $\mathrm{OR}=1.9$, the calculated predictive efficiency of this marker for the pooled group of patients was AUC = 0.54

\section{CONCLUSION}

Thus, the rs 2010963 polymorphism of the VEGFA gene is one of the main reasons for the dysregulation of the inflammatory and immune response of the body and, according to our data, the unfavorable C / G variant (associated with the overproduction of the proinflammatory cytokine VEGFA) may make a certain contribution to the development of ronchopathy with impaired nasal breathing.

\section{REFERENCES}

1. Camacho M, Guilleminault C, Wei JM, Song SA, Noller MW, Reckley LK, Fernandez-Salvador C, Zaghi S.Oropharyngeal and tongue exercises (myofunctional therapy) for snoring: a systematic review and meta-analysis.Eur Arch Otorhinolaryngol. 2018 Apr;275(4):849-855. [CrossRef]

2. Castaneda A., Jauregui-Maldonado E., Ratnani I., Varon J., Surani S. World J Diabetes. Correlation between metabolic syndrome and sleep apnea.2018 Apr 15;9(4):66-71. [CrossRef]

3. Cavuşoğlu M., Poets C.F., Urschitz M.S. Acoustics of snoring and automatic snore sound detection in children. Physiol Meas. 2017 Oct 31;38(11):1919-1938. [CrossRef]
4. Cazan D., Mehrmann U., Wenzel A., Maurer J.T. The effect on snoring of using a pillow to change the head position. Sleep Breath. 2017 Sep;21(3):615-621. [CrossRef]

5. Chang K.K., Kim K.B., McQuilling M.W., Movahed R. Fluid structure interaction simulations of the upper airway in obstructive sleep apnea patients before and after maxillomandibular advancement surgery. Am J Orthod Dentofacial Orthop. 2018 Jun;153(6):895-904. [CrossRef]

6. Charakorn N., Kezirian E.J. Drug-Induced Sleep Endoscopy. Otolaryngol Clin North Am. 2016 Dec;49(6):1359-1372. [CrossRef]

7. Chouard C.H., Valty J, Meyer B, Chabolle F, Fleury B, Véricel R, Laccourreye O, Josset P. Chronic rhonchopathy or snoring. Clinical aspects and therapeutic indications. Ann Otolaryngol Chir Cervicofac. 1986;103(5):319-27.

8. Chouard C.H. Did Napoleon suffer from chronic rhonchopathy? Acta Otolaryngol. 2017 Apr;137(4):361-364. [CrossRef]

9. Christiansz J.A., Lappin C.R., Weichard A.J., Nixon G.M., Davey M.J., Horne R.S.C., Biggs S.N. Slow wave activity and executive dysfunction in children with sleep disordered breathing. Sleep Breath. 2018 May;22(2):517-525. [CrossRef]

10. Costa G., De Benedetto M. Obstructive Sleep Apnea Syndrome (OSAS): Occupational Health and other medical disciplines facing the problem. Med Lav. 2017 Aug 28;108(4):247250.

11. Costa G. The obstructive sleep apnea syndrome (OSAS): implications for work and Occupational Health.Med Lav. 2017 Aug 28;108(4):251-259.

12. Cuda D., de Benedetto M., Graziuso M., Leante M. Test-retest reliability of anamnestic data on chronic obstructive apnea. ActaOtorhinolaryngol Ital. 1990 Nov-Dec;10(6):529-37. I 
13. De Benedetto M., Garbarino S., Sanna A. Obstructive sleep apnea (OSA): healthcare and social costs. Med Lav. 2017 Aug 28;108(4):310-313.

14. Deng Z.H., Li J.R., Hou Q., Chen N.N., Cui Z.Y., Li L.Z., Yang T.T., Liu J. Lin Chung Er Bi Yan HouTou Jing WaiKeZaZhi. Role of sleep apnea monitoring management platform in the treatment of patients with obstructivesleep apnea hypopnea syndrome.2017 Nov 5;31(21):1646-1648;1652.

15. DeRaaff CAL., de Vries N., van Wagensveld B.A. Obstructive sleep apnea and bariatric surgical guidelines: summary and update. CurrOpinAnaesthesiol. 2018 Feb;31(1):104-109. [CrossRef]

16. Di-Tullio F, Ernst G, Robaina G, Blanco M, Salvado A, Meraldi A, Bosio M, Borsini E. Sleep Sci. Ambulatory positional obstructive sleep apnea syndrome. 2018 Jan-Feb;11(1):8-11. [CrossRef]

17. Du Y.X., Zeng Y.M., Zhou Z.B., Huang L.M. ZhonghuaJie He He $\mathrm{Hu} \mathrm{Xi}$ ZaZhi.Assessment of sleep-disordered breathing using hypoxia index.2017 Sep 12;49(9):693-696.

18. Elizarova A.N., Raksha A.P., Grinchuk V.I. Clinicomorphological characteristics of the soft palate in patients with chronic ronchopathy. VestnOtorinolaringol. 2005;(3):20-4.

19. Elizarova L.N., Grinchuk V.I. General oxygen supply in males with rhonchopathy. Vestn Otorinolaringol. 2007;(6):43-7.

20. Esteller More E, Huerta Zumel P, Modolell Aguilar I, SegarraIsern F, MatiñóSoler E, Enrique González A, AdemàAlcover JM. Diagnosis of proximal gastro-oesophageal reflux in patients with rhonchopathy and sleep apnoea. Acta Otorrinolaringol Esp. 2007 Dec;58(10):464-9. [CrossRef]

21. Foroughi M., Malekmohammad M., Sharafkhaneh A., Emami H., Adimi P., Khoundabi B. Prevalence of Obstructive Sleep Apnea in a High-Risk Population Using the Stop-Bang Questionnaire in Tehran, Iran. Tanaffos. 2017;16(3):217-224.

22. García Castillo S., HoyosVázquez MDPS, Coloma Navarro R., Cruz Ruiz J., Callejas González F.J., Godoy Mayoral R., TárragaLópez P.J., Rodríguez Montes J.A. Obstructive sleep apnoea syndrome. AnPediatr (Barc). 2018 May;88(5):266-272. [CrossRef]

\section{AUTHORS PROFILE}

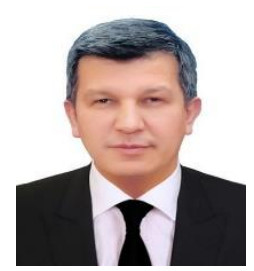

Khasanov Ulugbek Saidakramovich, Doctor of science, professor pf the department of Otolaryngology and stomatology of Tashkent Medical Academy, Republic of Uzbekistan, phone: +998908082971, mail: u.khasanov@yahoo.com

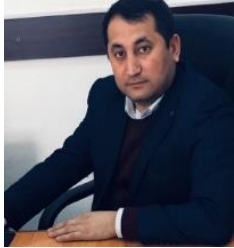

Sharipov Sanjar Salomovich, doctor of philosophy $(\mathrm{PhD})$, associate professor of the department of Otorhinolaryngology of Tashkent State Dental Institute, Republic of Uzbekistan, phone: +998977038543, mail: sanjar.shifo@mail.ru

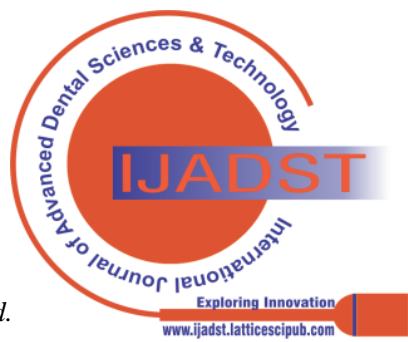

